\title{
Knowledge, Attitudes, and Practices towards COVID-19 among B.Sc. Nursing Students in Selected Nursing Institution in Saudi Arabia during COVID-19 Outbreak: An Online Survey
}

Dr. Farzana Begum*

Assistant professor, College of Applied Medical Science, Taif University, Saudi Arabia

DOI: $10.36348 /$ sjnhc.2020.v03i07.002

| Received: 01.07.2020 | Accepted: 10.07 .2020 | Published: 15.07 .2020

*Corresponding author: Dr. Farzana Begum

\section{Abstract}

Coronavirus disease 2019 (abbreviated "COVID- 19") is a highly contagious respiratory disease. It was first detected in December 2019 in Wuhan, China and since then it has spread across the globe and leads to many mortality and morbidity [1]. Therefore strict lockdown and many unprecedented measures have been adopted to control the rapid spread of the COVID-19 across the world. The effectiveness of these measures is highly dependent on cooperation of all members of society. People's adherence to preventive measures is markedly affected by their knowledge, attitude, and practices (KAP) towards COVID-19. Health care professional should have correct knowledge and fair attitude towards COVID-19, since they are the most influential community in health matters. In this study, KAP towards COVID-19 among the B.Sc. nursing students of Saudi Arabia was assessed. An online KAP questionnaire was answered by the participants. The questionnaire consisted of 15 knowledge, 10 attitude and 5 practice based questions. The average knowledge score for participants was 10.8. The overall correct answer rate of the knowledge questionnaire was $72 \%$. About $64 \%$ of participants were obtained scores above 10 . The majority of the respondents $72.6 \%$ were hopeful that world people will get rid of COVID-19 very soon, 79\% believe that hand hygiene and wearing a mask can help to prevent getting the infection, $90.3 \%$ agree that practicing quarantine by staying at home and avoiding crowded places can help prevent getting infection, $75.8 \%$ conscious about the guideline given by WHO, $88.7 \%$ agree that it is necessary to rub hands with soap or alcohol for at least 20 seconds, $96.8 \%$ agree that it is essential to maintain at least 1 meter physical distance to prevent getting infection, $71 \%$ believe that humanity, fraternity and empathy to one another help us fight against COVID19, 74.2\% believe that focusing on improving immune power is a good option to prevent getting infection, 38.7\%think that COVID-19 will remain in the world forever, $48.4 \%$ believe that people those are already recover from the disease also cannot transmit infection to others, $77.4 \%$ wash their hands frequently with soap and water for at least 20 to 40 seconds, $91.9 \%$ follow social distancing to avoid contact of infected persons, $83.9 \%$ avoid going crowded places these days, $75.8 \%$ practicing good respiratory hygiene and avoiding touching the eyes, nose or mouth with unwashed hands and $87.1 \%$ wore masks when going out in recent days. There was no significant difference found between the knowledgeable score of males and females about COVID-19. They hold optimistic attitudes, and have appropriate practices towards COVID-19.

Keywords: Knowledge, attitudes, practices, COVID-19, nursing, students, Saudi Arabia, online, survey.

Copyright @ 2020: This is an open-access article distributed under the terms of the Creative Commons Attribution license which permits unrestricted use, distribution, and reproduction in any medium for non-commercial use (NonCommercial, or CC-BY-NC) provided the original author and source are credited.

\section{INTRODUCTION}

Coronavirus disease 2019 (abbreviated "COVID- 19") is a highly contagious respiratory disease that is caused by a novel coronavirus and was first detected in December 2019 in Wuhan, China. The main clinical symptoms include fever, dry cough, fatigue, myalgia, and dyspnoea. The condition may range from asymptomatic mild to severe life threatening. The prognosis is bad mostly among those suffering from any pre-existing chronic illness and age above 50 yrs [1]. The battle against COVID-19 is still continuing in many parts of the world including Saudi Arabia.

Presently there are $191 \mathrm{k}$ confirmed cases of COVID19, 131k recovered and 1,649 deaths recorded from COVID19 in Saudi Arabia [2]. Therefore Saudi government has strictly implemented many unprecedented steps to make Saudi Arabia free from COVID19 [3]. 
To ensure success, people's adherence to the preventive measures is essential, which is largely influenced by their knowledge, attitude, and practices (KAP) towards COVID-19 [4, 5]. Lessons learned from the SARS outbreak in 2003 suggest that knowledge and attitude towards contagious diseases are associated with the level of panic emotion among the population [6, 7]. In the current study, the KAP towards COVID-19 of B.Sc. nursing students of Saudi Arabia is investigated to know their awareness.

\section{METHODS}

This is a quantitative cross-sectional study. Data collected online due to the lockdown and annual vacation of the students. Since not enough responses received after several reminders, data collection time for this survey was extended from May 28 to June 30 and, still only 124 responses found.

The questionnaire is an adaptation of the measures developed in a study on Chinese residents' knowledge, attitudes and practices (KAP) towards COVID-19 in China had demographic variables included age and gender and 15 knowledge based, 10 attitude based and 5 practice based questions [8]. The knowledge questions were answered on a true/false and "not sure" basis. A correct answer was assigned 1 point and an incorrect/unknown answer was assigned 0 . The total knowledge score ranged from 0 to 15 , with a higher score denoting a better knowledge of COVID-
19. The attitude based questions also answered on a true/false and "not sure" basis. The practice based questions were answered on a true/false and "sometimes" basis.

Permission taken from the Dean of the selected nursing institute to conduct the study. Participants had to answer a yes-no question to confirm their willingness to participate in the study voluntarily and after confirmation of the question, the participant was directed to complete the self-report questionnaire.

For this study, the collected data were analysed by frequencies and percentage to focus on descriptive analysis and independent sample t-test used to determine the difference between knowledge scores of males and females.

\section{RESULTS}

A total of 124 participants with the average age 23 years, male $62(50 \%)$ and female $62(50 \%)$ were responded the survey questionnaire.

A total of fifteen questions were used to measure knowledge on the COVID-19. The average knowledge score for participants was 10.8. The overall correct answer rate of the knowledge questionnaire was $72 \%(10.8 / 15 * 100)$. About $64 \%$ of participants were obtained scores above 10 .

Table-1: Level of knowledge of participants towards COVID-19 N=124

\begin{tabular}{|c|c|c|c|}
\hline Knowledge questions & Yes & No & Not sure \\
\hline K1. Is COVID-19 caused by covid virus? & $106(85.5 \%)$ & $8(6.5 \%)$ & $10(8.1 \%)$ \\
\hline $\begin{array}{l}\text { K2. Is the disease name suggested as COVID-19 since it was first identified } \\
\text { in } 2019 \text { ? }\end{array}$ & $92(74.2 \%)$ & $16(12.9 \%)$ & $16(12.9 \%)$ \\
\hline K3. Is covid-19 highly infectious? & $116(93.5 \%)$ & $6(4.8 \%)$ & $2(1.6 \%)$ \\
\hline $\begin{array}{l}\text { K4. Are the main clinical symptoms of COVID-19 are fever, fatigue, dry } \\
\text { cough and myalgia? }\end{array}$ & $114(91.9 \%)$ & $4(3.2 \%)$ & $6(4.8 \%)$ \\
\hline $\begin{array}{l}\text { K5. Unlike the common cold, stuffy nose, runny nose and sneezing are less } \\
\text { common in persons suffering from COVID-19. }\end{array}$ & 72(58.1\%) & $34(27.4 \%)$ & $18(14.5 \%)$ \\
\hline $\begin{array}{l}\text { K6. Is COVID-19 makes the condition worse among those are elderly or } \\
\text { suffering from chronic illness like heart disease, lung or kidney disease? }\end{array}$ & $120(96.8 \%)$ & $2(1.6 \%)$ & $2(1.6 \%)$ \\
\hline K7. Eating non-veg food or contacting with pets may cause COVID-19. & $30(24.2 \%)$ & $70(56.5 \%)$ & $24(19.4 \%)$ \\
\hline K8. Can asymptomatic COVID-19 cases transmit infection to others? & $94(75.8 \%)$ & $16(12.9 \%)$ & $14(11.3 \%)$ \\
\hline K9. Can the disease transmit through the droplets of an infected individual? & $96(77.4 \%)$ & $8(6.5 \%)$ & $20(16.1 \%)$ \\
\hline K10. Do children and young adults also need preventive measures? & $114(91.9 \%)$ & $8(6.5 \%)$ & $2(1.6 \%)$ \\
\hline K11. A nasopharyngeal swab testing may confirm the diagnosis. & $108(87.1 \%)$ & $14(11.3 \%)$ & $2(1.6 \%)$ \\
\hline K12. Is there any vaccine of COVID $-19 ?$ & $6(4.8 \%)$ & $92(74.2 \%)$ & $26(21 \%)$ \\
\hline $\begin{array}{l}\text { K13. Do you think isolation and supportive treatment of the infected are the } \\
\text { effective measures to control spread of infection? }\end{array}$ & $112(90.3 \%)$ & $6(4.8 \%)$ & $6(4.8 \%)$ \\
\hline $\begin{array}{l}\text { K14. Is it essential that people who exposed to infected persons should be } \\
\text { quarantine for a minimum of } 14 \text { days period? }\end{array}$ & $104(83.9 \%)$ & $6(4.8 \%)$ & $14(11.3 \%)$ \\
\hline K15. Are mask and hand-gloves fruitful to prevent the infection? & $106(85.5 \%)$ & $6(4.8 \%)$ & $12(9.7 \%)$ \\
\hline
\end{tabular}

*bold are the correct answers

Table - 1 depicts almost all participants $96.8 \%$ knows that COVID-19 makes the condition worse among those are elderly or suffering from chronic illness like heart disease, lung or kidney disease, $93.5 \%$ agree that covid-19 is highly infectious, $91.9 \%$ have the knowledge that the main clinical symptoms of COVID- 
19 are fever, fatigue, dry cough and myalgia and children and young adults also need preventive measures, $90.3 \%$ think isolation and supportive treatment of the infected are the effective measures to control spread of infection, $87.1 \%$ agree that a nasopharyngeal swab testing may confirm the diagnosis, $85.5 \%$ believe that mask and hand-gloves fruitful to prevent the infection, $83.9 \%$ agree that it is essential that people who exposed to infected persons should be quarantine for a minimum of 14 days period, $77.4 \%$ agree that the disease can transmit through the droplets of an infected individual, $74.2 \%$ knows the reason why the name suggested as COVID-19 and there is no vaccine available till now for COVID-19, $58.1 \%$ agree that unlike the common cold, stuffy nose, runny nose and sneezing are less common in persons suffering from COVID-19, 56.5\% believe that eating non-veg food or contacting with pets cannot cause COVID-19, $12.9 \%$ agree that asymptomatic COVID-19 cases cannot transmit infection to others and only $6.5 \%$ knows that COVID-19 is not due to covid virus.

Table-2: Comparison between knowledge score of males and females $\mathrm{N}=124$

\begin{tabular}{|c|c|c|c|c|}
\hline Variable & Gender & Frequency & Mean & p value \\
\hline Knowledge score & Male & 62 & 11.61 & 0.3 \\
\cline { 2 - 4 } & Female & 62 & 10.06 & \\
\hline \multicolumn{4}{c}{ *Independent t-test applied } \\
\hline
\end{tabular}

There was no significant difference found between the knowledge score of males and females since, $\mathrm{p}=0.3$ which is more than the significant level 0.0 (Table-2).

Table-3: Age based comparison of knowledge score $\mathrm{N}=124$

\begin{tabular}{|c|c|c|c|c|}
\hline Variable & Age & Frequency & Mean & p value \\
\hline Knowledge score & $<23$ years & 76 & 10.7 & \multirow{2}{*}{0.8} \\
\cline { 2 - 4 } & \multicolumn{5}{|c|}{ *23 years } & 48 & 10.9 & \\
\hline
\end{tabular}

*Independent t-test applied

There was no significant difference between the knowledge score based on age of the participants since, $\mathrm{p}=0.8$ which is more than the level of significance 0.05 . (Table-2)

Table-4: Attitude of participants towards COVID-19 N=124

\begin{tabular}{|c|c|c|c|}
\hline Attitude questions & Yes & No & Not sure \\
\hline A1. Are you hopeful that world people will get rid of COVID-19 very soon? & $90(72.6 \%)$ & $14(11.3 \%)$ & $20(16.1 \%)$ \\
\hline $\begin{array}{l}\text { A2. Do you believe that hand hygiene and wearing a mask can help to } \\
\text { prevent getting the infection? }\end{array}$ & $98(79 \%)$ & $8(6.5 \%)$ & $18(14.5 \%)$ \\
\hline $\begin{array}{l}\text { A3. Do you agree that practicing quarantine by staying at home and avoiding } \\
\text { crowded places can help prevent getting infection? }\end{array}$ & $112(90.3 \%)$ & $8(6.5 \%)$ & $4(3.2 \%)$ \\
\hline A4. Are you conscious about the guideline given by WHO? & $94(75.8 \%$ & $22(17.7 \%)$ & $8(6.5 \%)$ \\
\hline A5. Is it necessary to rub hands with soap or alcohol for at least 20 seconds? & $110(88.7 \%)$ & $8(6.5 \%)$ & $6(4.8 \%)$ \\
\hline $\begin{array}{l}\text { A6. Is it essential to maintain at least } 1 \text { meter physical distance to prevent } \\
\text { getting infection? }\end{array}$ & $120(96.8 \%)$ & $0(0 \%)$ & $4(3.2 \%)$ \\
\hline $\begin{array}{l}\text { A7. Can humanity, fraternity and empathy to one another help us fight } \\
\text { against COVID-19? }\end{array}$ & $88(71 \%)$ & $14(11.3 \%)$ & $22(17.7 \%)$ \\
\hline $\begin{array}{l}\text { A8. Do you believe that focusing on improving immune power is a good } \\
\text { option to prevent getting infection? }\end{array}$ & $92(74.2 \%)$ & $26(21 \%)$ & $6(4.8 \%)$ \\
\hline A9. Do you think that COVID-19 will remain in the world forever? & $48(38.7 \%)$ & $40(32.3 \%)$ & $36(29 \%)$ \\
\hline $\begin{array}{l}\text { A10. Do you think that people those are already recovering from the disease } \\
\text { also can transmit infection to others? }\end{array}$ & $48(38.7 \%)$ & $60(48.4 \%)$ & $16(12.9 \%)$ \\
\hline
\end{tabular}

Table -4 shows that most of the participants, $96.8 \%$ agree that it is essential to maintain at least 1 meter physical distance to prevent getting infection, $90.3 \%$ agree that practicing quarantine by staying at home and avoiding crowded places can help prevent getting infection, $88.7 \%$ believe that it is necessary to rub hands with soap or alcohol for at least 20 seconds, $79 \%$ believe that hand hygiene and wearing a mask can help to prevent getting the infection, $75.8 \%$ conscious about the guideline given by WHO, $74.2 \%$ believe that focusing on improving immune power is a good option to prevent getting infection, $72.6 \%$ were hopeful that world people will get rid of COVID-19 very soon,71\% believes that humanity, fraternity and empathy to one another help us fight against COVID-19, 38.7\% think that COVID-19 will remain in the world forever and people those are already recover from the disease also can transmit infection to others. 
Table-5: Practice of participants towards COVID-19N=124

\begin{tabular}{|l|c|c|c|}
\hline \multicolumn{1}{|c|}{ Practice questions } & Yes & No & Sometimes \\
\hline $\begin{array}{l}\text { P1. Do you wash your hands frequently with soap and water for at least 20 to } \\
\text { 40 seconds? }\end{array}$ & $96(77.4 \%)$ & $16(12.9 \%)$ & $12(9.7 \%)$ \\
\hline P2. Do you follow social distancing to avoid contact of infected persons? & $114(91.9 \%)$ & $0(0 \%)$ & $10(8.1 \%)$ \\
\hline P3. Do you avoid going crowded places these days? & $104(83.9 \%)$ & $6(4.8 \%)$ & $14(11.3 \%)$ \\
\hline $\begin{array}{l}\text { P4. Do you practicing good respiratory hygiene and avoiding touching the } \\
\text { eyes, nose or mouth with unwashed hands? }\end{array}$ & $94(75.8 \%)$ & $8(6.5 \%)$ & $22(17.7 \%)$ \\
\hline P5. Do you use mask while going outside? & $108(87.1 \%)$ & $6(4.8 \%)$ & $10(8.1 \%)$ \\
\hline
\end{tabular}

Table -5 depicts that maximum participants 91.9\% reported that they follow social distancing to avoid contact of infected persons, $87.1 \%$ use mask always while going out, $83.9 \%$ avoid going crowded places these days and $77.4 \%$ wash hands frequently with soap and water for at least 20 to 40 seconds.

\section{DISCUSSION}

COVID-19 is a newly found virus that has devastating impact within a very short period since it was first detected in December 2019. There are very few published data on population knowledge, attitudes and practices toward COVID-19 available till now. The novelty of the disease, and its uncertainties, make it difficult for health authorities to plan appropriate strategies to prepare the public. It is therefore of important to assess the knowledge, attitudes and practices of the population to guide these efforts.

The average knowledge score for participants in regards to COVID-19 was 10.8. Several studies have shown high levels of COVID-19 knowledge among the general population [8] and healthcare professionals [9]. Due to differences in analysis and scoring systems it is not possible for accurate comparisons of knowledge levels across these studies. The present study found that a majority of participants held positive attitudes toward overcoming COVID-19. High levels of positive attitudes were also detected in the KAP study conducted in China and Malayesia [8, 10]. The swift action taken by the Saudi government in enforcing various measures to control and manage the spread of infection may have also contributed to the positive attitudes. Though the percentage of participants reporting uncertainty toward success in fighting against COVID-19 was low (16.1\%) scores.

In the current study, most participants reported taking precautions such as avoiding crowded places, maintaining social distancing and practicing proper hand hygiene indicates a general willingness to make behavioural changes towards COVID-19 pandemic.

The current survey indicates the need for more comprehensive education programmes and focus on misinformation in the form of conflicting opinions.

\section{LIMITATIONS}

The questionnaire shared through google form link and it was ignored by most of the participants.

\section{CONCLUSIONS}

The current study provides a comprehensive assessment of the knowledge, attitudes and practices of Saudi nursing students toward COVID-19. The findings suggest that Saudi nursing students have an acceptable level of knowledge and positive outlook towards COVID-19 on overcoming the pandemic. Consistent information from the government and/ or health authorities are key to aid knowledge and understanding of COVID-19. Specific health education programs also can raise COVID-19 knowledge and improve practices.

\section{ACKNOWLEDGEMENTS}

The author thanks all the participants for their participation and support.

\section{Competing Interests}

No competing interest exists

\section{REFERENCES}

1. Coronavirus disease. (2019). available at https://en.wikipedia.org/wiki/Coronavirus_disease _2019 accessed on 30/06/2020

2. Corona Tracker available at https://www.coronatracker.com/country/saudiarabia/ accessed on 30/06/2020

3. Measures taken by Saudi Arabia to combat the coronavirus available at https:/english.alarabiya.net/en/features/2020/03/2 8/Timeline-Saudi-Arabia-s-proactive-measures-tocombat-the-COVID-19-coronavirus accessed on 30/06 /2020

4. Ajilore, K., Atakiti, I., \& Onyenankeya, K. (2017). College students' knowledge, attitudes and adherence to public service announcements on Ebola in Nigeria: Suggestions for improving future Ebola prevention education programmes. Health Education Journal, 76(6), 648-660.

5. Tachfouti, N., Slama, K., Berraho, M., \& Nejjari, C. (2012). The impact of knowledge and attitudes on adherence to tuberculosis treatment: a casecontrol study in a Moroccan region. Pan African Medical Journal, 12(1). 
6. Person, B., Sy, F., Holton, K., Govert, B., \& Liang, A. (2004). Fear and stigma: the epidemic within the SARS outbreak. Emerging infectious diseases, 10(2), 358.

7. Tao, N. (2003). An analysis on reasons of SARSinduced psychological panic among students. Journal of Anhui Institute of Education, 21: 78-9.

8. Zhong, B. L., Luo, W., Li, H. M., Zhang, Q. Q., Liu, X. G., Li, W. T., \& Li, Y. (2020). Knowledge, attitudes, and practices towards COVID-19 among Chinese residents during the rapid rise period of the COVID-19 outbreak: a quick online cross-sectional survey. International journal of biological sciences, 16(10), 1745.

9. Giao, H., Thi, N., Han, N., Khanh, T. V., Ngan, V. K., \& Tam, V. Knowledge and attitude toward COVID-19 among healthcare workers at Knowledge and attitude toward COVID-19 among healthcare workers at District 2 Hospital, Ho Chi Minh City. Asian Pac J Trop Med 2020; 13: 1-6.

10. Azlan, A. A., Hamzah, M. R., Sern, T. J., Ayub, S. H., \& Mohamad, E. (2020). Public knowledge, attitudes and practices towards COVID-19: A cross-sectional study in Malaysia. Plos one, 15(5), e0233668. 